\title{
Burbank Transportation Management Organization: Impact Analysis
}

Technical Report NREL/TP-640-40507

November 2006

E. Brown and J. Aabakken 


\section{Burbank Transportation Management Organization: Impact Analysis}

E. Brown and J. Aabakken

Prepared under Task No. WW98.1000
Technical Report NREL/TP-640-40507

November 2006

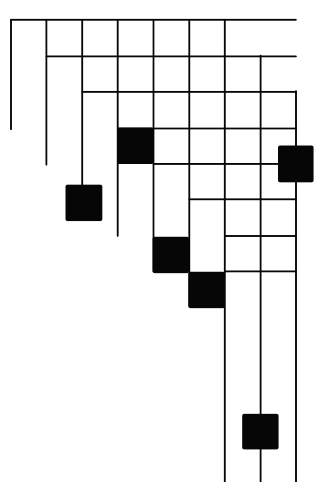




\section{NOTICE}

This report was prepared as an account of work sponsored by an agency of the United States government. Neither the United States government nor any agency thereof, nor any of their employees, makes any warranty, express or implied, or assumes any legal liability or responsibility for the accuracy, completeness, or usefulness of any information, apparatus, product, or process disclosed, or represents that its use would not infringe privately owned rights. Reference herein to any specific commercial product, process, or service by trade name, trademark, manufacturer, or otherwise does not necessarily constitute or imply its endorsement, recommendation, or favoring by the United States government or any agency thereof. The views and opinions of authors expressed herein do not necessarily state or reflect those of the United States government or any agency thereof.

Available electronically at http://www.osti.gov/bridge

Available for a processing fee to U.S. Department of Energy and its contractors, in paper, from:

U.S. Department of Energy

Office of Scientific and Technical Information

P.O. Box 62

Oak Ridge, TN 37831-0062

phone: 865.576 .8401

fax: 865.576 .5728

email: mailto:reports@adonis.osti.gov

Available for sale to the public, in paper, from:

U.S. Department of Commerce

National Technical Information Service

5285 Port Royal Road

Springfield, VA 22161

phone: 800.553.6847

fax: 703.605.6900

email: orders@ntis.fedworld.gov

online ordering: http://www.ntis.gov/ordering.htm 


\title{
Introduction by the BTMO
}

\author{
Dear Reader,
}

Thank you for your interest in the Burbank Transportation Management Organization (BTMO). The following report, prepared by the National Renewable Energy Laboratory (NREL), a national laboratory of the United States Department of Energy, is based on data provided to the BTMO by its members for years 1992 through 2005, and presents findings that show the impact of BTMO programming.

Founded in 1989, and located in Burbank, California, the BTMO is a private-sector, dues-based nonprofit organization dedicated to reducing traffic and improving air quality. The BTMO integrates land use, transportation, air quality, and energy planning and programming to implement cooperative and creative solutions that address issues directly affecting its members and possibly impacting the citizens of Burbank. One key BTMO function is to develop, implement, manage, monitor, and measure transportation demand-management programs. The provisions of these BTMO programs allow its members to better meet company, employee, customer, and regulatory needs.

While the BTMO's members are primarily in the following two commercial planning areas, its membership is not limited to those areas:

1) The Media District (commercial use prescribed by the Media District Specific Plan [MDSP]); and

2) The Downtown Redevelopment Area (prescribed by the Burbank Center Plan [BCP]).

Both the MDSP and the BCP traffic-reduction elements reinforce BTMO programs and substantiate the work of BTMO members who were actively reducing traffic and implementing clean air programming several years prior to the passage of either the MDSP or BCP ordinances.

Currently, the BTMO membership includes more than 100 employers. Over the years, the BTMO has created and implemented the following transportation demand-management strategies:

- employee flex time and modified work schedules;

- vanpool and carpool programs;

- rail, bus, and shuttle programs;

- satellite parking;

- non-vehicular commuting;

- parking management;

- merchant incentives for commuters; and

- telecommuting programs.

Specifically, the BTMO created:

- Burbank's first Flat Rate Taxi Program;

- Burbank's first On-Demand Commuter Rail Shuttle Service;

- Burbank's first Fixed Route Metrolink Shuttle Service; 
- Burbank's first Clean Fuel Shuttle Service;

- Burbank's first Home-to-Work Shared Taxi Program;

- Burbank's first Noon-Time Work-to-Lunch Taxi Program;

- Burbank's first Senior Citizen Holiday Taxi Program;

- Direct-route shuttle services for individual member companies;

- Emergency transportation services, following the Northridge Earthquake;

- Middle School Traffic Reduction and Clean Air Curriculum;

- Middle School Student Art and Writing Contests;

- Lower Metrolink fares for Burbank riders through negotiations;

- Alternative Fuels and Electric Bike Demonstration Projects;

- Electric Vehicle Charging Station funding acquisition and siting;

- Air quality compliance programming;

- Emergency preparedness workshops and member network;

- New transit technology integration into member-company fleets;

- May "Clean Air Month" celebrations and benefit programs;

- Member information and education sessions; and

- Individual member company consultation and data collection services.

To better evaluate its work over the years, the BTMO commissioned NREL to evaluate the direct and indirect impacts of BTMO programs and their overall effectiveness. While the BTMO has not collected member services data for all of its programs, it has been collecting member company employee commute data since 1992. Because this was the only formal survey information available to NREL, additional analysis by NREL was performed to determine the indirect impacts of the BTMO programs. The indirect impacts include the effects on the environment, gasoline consumption, and the amount of time and money spent commuting.

The NREL report, which follows, uses data submitted to the BTMO by its members during the BTMO "Clean Air Week" (the first full week of May each year) for years 1992 through 2005. BTMO member employers are requested to survey each full- and part-time employee during "Clean Air Week" to determine commute behavior. Employer information is then given to the BTMO, which enables the BTMO to release an annual collective BTMO membership public report. Other employer data provided to the BTMO (especially during years 1989 through 1991) is related to the Air Quality Management District (“AQMD”) and only applies to large employers. After careful consideration, NREL determined the BTMO "Clean Air Week" employee data to be the most consistently collected and most appropriate for use as the baseline in its analysis of BTMO programming.

The NREL analysis follows. The BTMO thanks NREL for its thoroughness but especially thanks and congratulates the entire BTMO membership, which has proven with its hard work and dedication that creative, collective, cost-effective programs are possible and can significantly improve traffic and our environment.

Signed,

BTMO Management 


\section{Purpose of Analysis}

The Burbank Transportation Management Organization (BTMO), a private, membership-based, nonprofit organization dedicated to traffic reduction and air quality improvement, contracted with the National Renewable Energy Laboratory (NREL), a U.S. Department of Energy-owned, contractor-operated national laboratory, to analyze its member programs and their benefits and effects. This report uses trip data collected by the BTMO, and defines and implements a methodology for quantifying the following non-traffic benefits:

- Gasoline savings (gallons avoided). Avoided gasoline use is the result of reduced trip frequency and length. The BTMO programs focus on single-driver commuter reductions and the avoidance of trips. As a result, there is a decreased demand for gasoline. ${ }^{1}$

- Pollution-reduction impacts (CO, VOC, $\mathrm{NOx}$, and $\mathrm{CO}_{2}$ equivalents avoided). Pollution reductions are the direct result of vehicles not running on the roads. Reductions contribute to the improvement of local air quality and decreased greenhouse gas emissions in the immediate and surrounding areas.

- Productivity benefits (commute time savings). Time spent sitting in traffic is time one cannot spend elsewhere. The time gained by not sitting in traffic is a benefit. This benefit, depending on the use of the time saved by choosing an alternative to driving alone, is considered a quality-of-life benefit to either the commuter or the member company. This report does not quantify the distribution of the benefits.

- Limited economic benefits (costs avoided). Reduced gasoline purchases and increased productivity have measurable economic benefits illustrating the impact of the program.

\section{Results Summary}

The benefits of the BTMO traffic-reduction programs are evaluated using data collected for years 1992 through 2005 and reported to the BTMO by its members. Table 1 illustrates the results of the analysis. For years 1992 through 2005, BTMO members reported a reduction of 68 million trips, equating to an annual average reduction of 4.9 million trips. That trip reduction translates into an estimated cumulative 1 billion avoided vehicle miles traveled. The reduced number of trips results in avoided emissions of pollutants; which, when combined with vehicle technology improvements, include reductions of 1,400 tons of nitrogen oxides, 21,000 tons of carbon monoxide, and 2,100 tons of volatile organic compounds (VOCs). Emissions impacts can also be measured in carbon dioxide equivalents $\left(\mathrm{CO}_{2} \mathrm{eq}\right)$, a useful metric in terms of climate change. Based on the number of gallons of gasoline not used as a result of member company participation, the cumulative $\mathrm{CO}_{2}$ eq emissions avoided are approximately 425,000 tons.

Benefits of member-company participation in the BTMO trip-reduction programs can also be quantified by estimating increased employee productivity and gasoline cost savings for the same time period. Employee productivity increased directly (in terms of hours) and indirectly (in terms of implied cost savings). Direct benefits are measured in terms of time saved for commuters not making solo vehicular trips, but rather choosing to travel by public transportation, carpooling,

\footnotetext{
${ }^{1}$ Analysis assumes all vehicles are gasoline powered.
} 
vanpooling, walking, biking, working a flex-time schedule, or telecommuting - thus, spending less time in traffic and increasing productivity by using the saved time as productive time. From 1992 through 2005, the estimated direct productivity savings are 42 million hours. The equivalent estimated indirect cost savings for the same time period are $\$ 584$ million, and the gasoline cost savings to commuters are estimated to be $\$ 74$ million. Thus, there is a cumulative estimated cost savings of more than $\$ 658$ million. Note that these estimates are not specific to any member company or the commuter, but assume that the full amount of time and money saved by not commuting alone is not spent commuting at different times or through different modes of travel.

Table 1. Summary Benefits of BTMO Trip-Reduction Programs (1992-2005)

\begin{tabular}{|c|c|c|c|}
\hline \multicolumn{2}{|c|}{ Metric } & Average Annual & Cumulative Total \\
\hline \multicolumn{2}{|c|}{ Trips Reduced (one way) } & $4,900,000$ & $68,000,000$ \\
\hline \multicolumn{2}{|c|}{$\begin{array}{l}\text { Vehicle Miles Traveled }{ }^{2} \text { Reduction } \\
\text { (miles) }\end{array}$} & $78,000,000$ & $1,090,000,000$ \\
\hline \multirow{4}{*}{$\begin{array}{l}\text { Pollutants } \\
\text { Avoided (tons)* }\end{array}$} & $\mathrm{CO}$ & 660 & 9,300 \\
\hline & NOx & 60 & 840 \\
\hline & VOC & 79 & 1,100 \\
\hline & $\mathrm{CO}_{2} \mathrm{eq}$ & 30,400 & 425,000 \\
\hline \multicolumn{2}{|c|}{ Gasoline Savings (gal.) } & $3,000,000$ & $44,000,000$ \\
\hline \multicolumn{2}{|c|}{ Employee Productivity (hours) } & $3,000,000$ & $42,000,000$ \\
\hline \multicolumn{2}{|c|}{ Economic Benefits ${ }^{* *}(\$)$} & $47,000,000$ & $658,000,000$ \\
\hline \multicolumn{4}{|c|}{$\begin{array}{l}\text { *Emissions from } \mathrm{CO}, \mathrm{NOx} \text {, and } \mathrm{VOC} \text { are not additive with } \mathrm{CO}_{2} \text { eq emissions, } \\
\text { because the methodology for determining } \mathrm{CO}_{2} \text { eq incorporates all emissions avoided } \\
\text { from avoided gasoline combustion. Global climate change is conventionally } \\
\text { measured by combining pollutants into their carbon dioxide equivalence }\left(\mathrm{CO}_{2} \mathrm{eq}\right) \\
\text { using a weighting system for different pollutants based on their atmospheric impact. } \\
\text { Emissions reported result only from the BTMO program, not technology } \\
\text { developments (identified in the text). Methodologies and overall emissions from } \\
\text { combined BTMO program and technology improvements are listed in detail in the } \\
\text { body of the report. }\end{array}$} \\
\hline
\end{tabular}

While the data used as the basis for this study is the most consistently collected data available, it is limited in its direct use. For example, the data collected was targeted at measuring traffic congestion reductions during the 4-6 p.m. peak traffic hours. Because the BTMO data collection survey was not designed to measure ancillary impacts such as gasoline savings or emissions reductions, the results presented here are preliminary and based on extrapolations from the 4-6 p.m. time period data collected each year during "Clean Air Week" (the first full week of May).

While this analysis does not address the benefits to the general Southern California population resulting from the BTMO trip-reduction programs, traffic reductions do have ancillary benefits such as increased productive time and less automobile idling time (leading to gasoline savings

\footnotetext{
${ }^{2}$ Vehicle miles traveled (VMT) is a measurement of the average number of miles traveled by vehicles in a given area (Burbank and the surrounding areas, in this case).
} 
and pollution reductions). The benefits of the BTMO activities to nonmembers, Burbank residents, and others in the Los Angeles area are not measured in this report. The recommendations listed at the end of this report identify strategies for maximizing and accurately documenting the ancillary benefits of the BTMO programs.

\section{BTMO Program Benefits}

Reductions in BTMO member-company average daily trips are shown in Figure 1. Fluctuations in the data result from a number of external and internal factors. Externally, data fluctuations result from changing gas prices and employee population changes within each member company. Internal factors affecting the analysis include changes in BTMO programs and data collection. For example, trip reductions increased in 1998, when the BTMO began requesting member companies in the Downtown Redevelopment Area [Burbank Center Plan (BCP)] to survey employees and be included in the BTMO data collection. Another example is from 2003, when data collection methods were expanded and updated to include more descriptive land-use types (i.e., retail categories were no longer generalized), which may have had an impact on the raw data. While not specifically measured in this report, the change in data collection and reporting categories may have an impact on the evaluation of benefits. Recommendations regarding future data collection to account for these issues are listed at the end of this report. Results based on this data should be qualified with the base-data uncertainties.

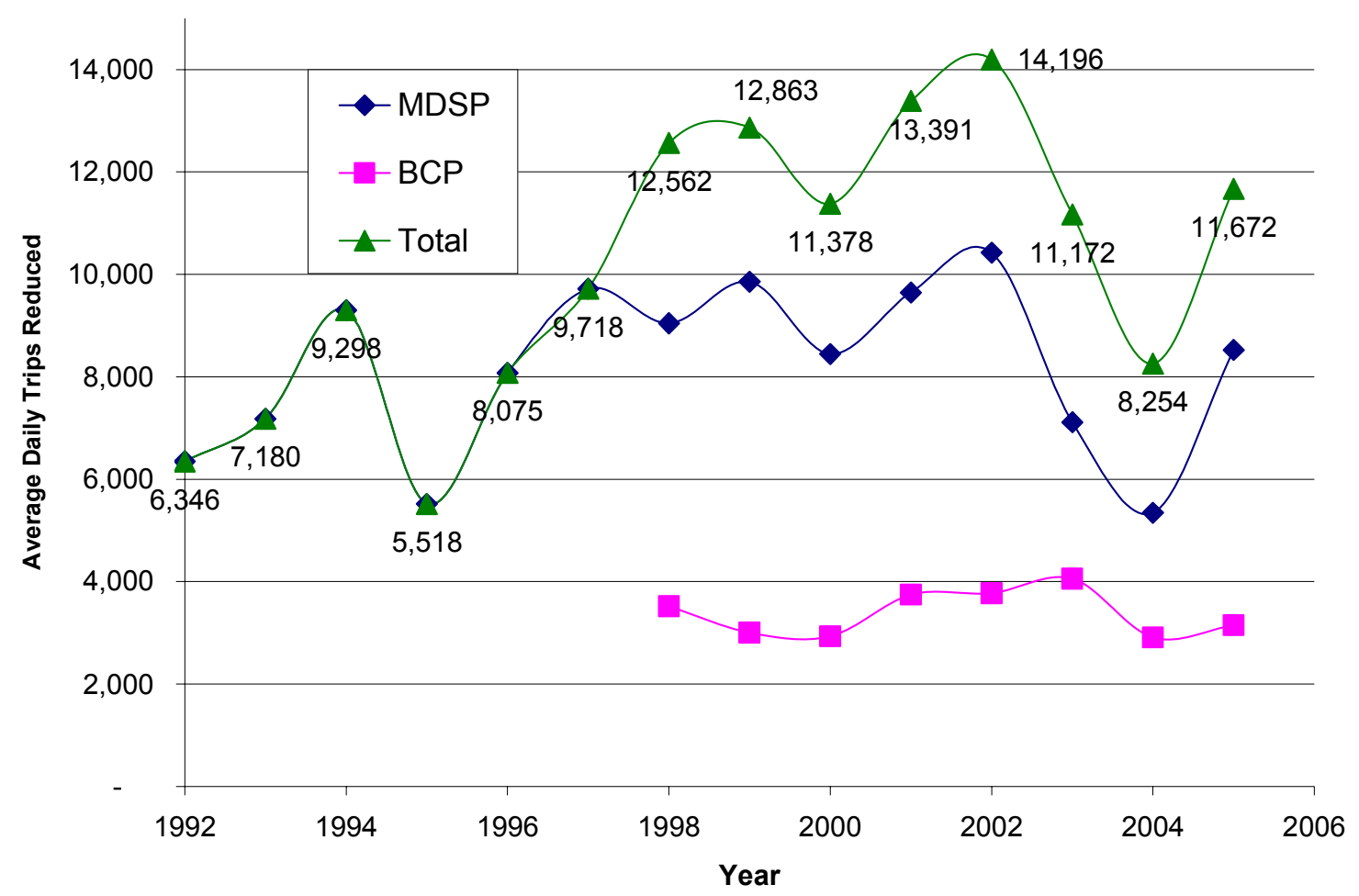

Figure 1. Average Daily Trips Reduced by BTMO Member-Company Employees 
A reduction in solo-driver commuter trips is a benefit not only to BTMO member companies and their employees, but also a benefit to the community and the region. This report uses the trip data collected by the BTMO, and defines and implements a methodology for quantify the following non-traffic benefits:

- Gasoline savings (gallons avoided). Avoided gasoline use is the result of reduced trip frequency and length. The BTMO programs focus on single-driver commuter reductions and the avoidance of trips. As a result, demand for gasoline is avoided through the BTMO programs. ${ }^{3}$

- Pollution-reduction impacts ( $\mathrm{CO}, \mathrm{VOC}, \mathrm{NOx}$, and $\mathrm{CO}_{2}$ equivalents avoided). Pollution reductions are the direct result of vehicles not running on the roads. Reductions contribute to the improvement of local air quality and decreased greenhouse gas emissions in the immediate and surrounding areas.

- Productivity benefits (commute time savings). Time spent sitting in traffic is time one cannot spend elsewhere. The time not sitting in traffic is a benefit. This benefit, depending on the use of the time saved by choosing an alternative to driving alone, is considered a quality-of-life benefit to either the commuter or the member company. This report does not quantify the distribution of the benefits, but the total time savings.

- Limited economic benefits (costs avoided). Avoided gasoline purchases and increased productivity have measurable economic benefits illustrating the impact of the program.

To determine the program benefits for the BTMO trip-reduction programs, the number of travel miles avoided must be calculated to quantify multiple benefits. To do so, it is assumed that a trip avoided between 4 and 6 p.m. mirrors a morning trip avoided, and the five-day employee data submitted by each member company to the BTMO is reflective of employee-commute activity for an annual work year consisting of 240 days. A trip, then, is defined as a one-way, solo-driver vehicle commute. The resulting cumulative number of trips avoided is 68 million (1992 through 2005), an average of 4.9 million trips reduced annually (Figure 2).

\footnotetext{
${ }^{3}$ Analysis assumes all vehicles are gasoline powered.
} 


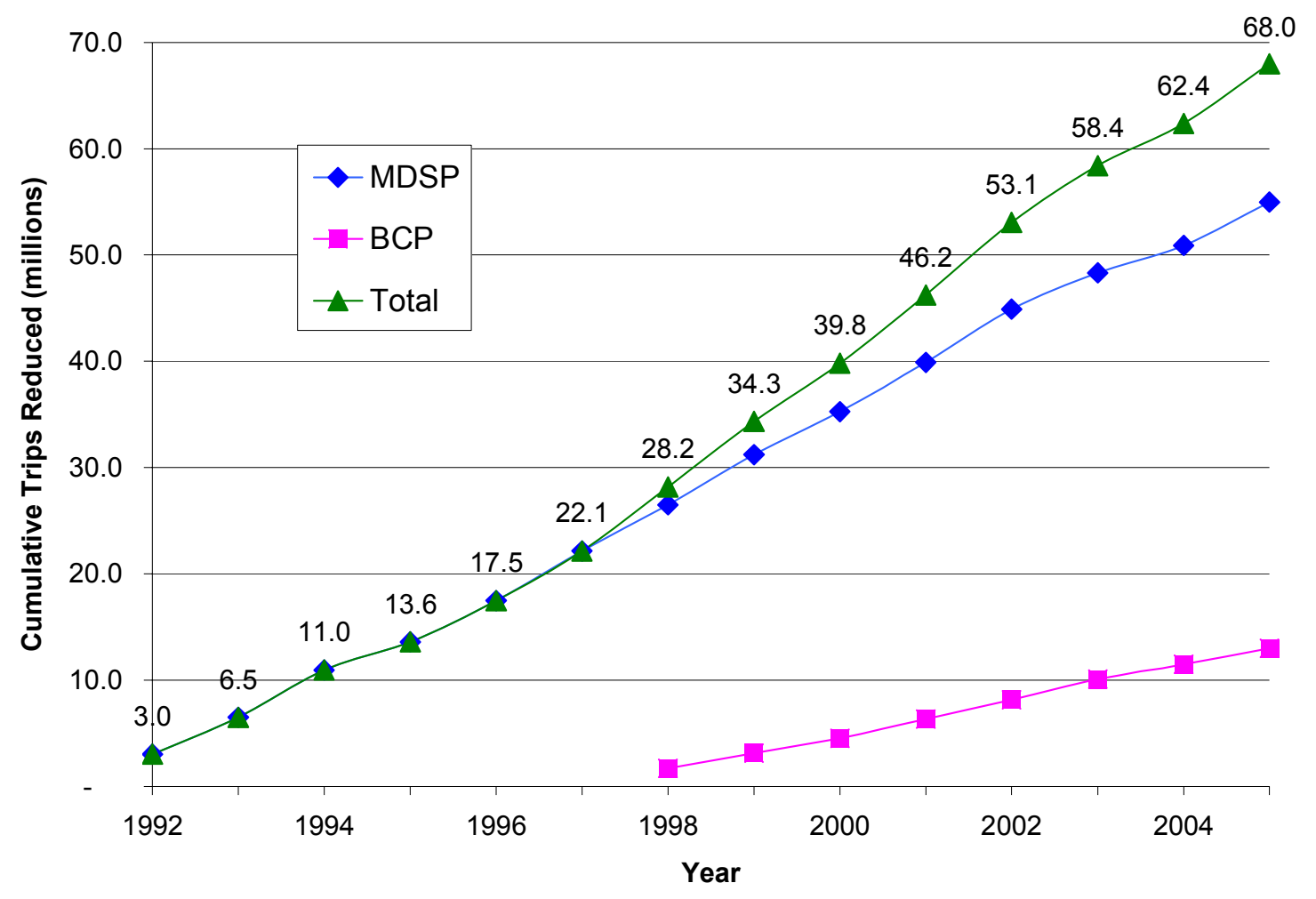

Figure 2. Cumulative Trip Reductions Attributed to BTMO Member-Company Employees

The number of trips avoided, coupled with average trip length, provides the measurement for the total number of avoided vehicle miles traveled (VMT). VMT is useful in measuring program impact, because the average number of miles traveled per vehicle correlates to a reduction in emissions, congestion, and gasoline consumption (see following sections). VMT reduction estimates are developed by multiplying the number of trips avoided by the average distance per trip.

To determine the average distance per trip, population-weighted ZIP code data was used in conjunction with a geographic information system (GIS) to calculate estimates of straight-line distances from employees' home areas to central Burbank. By excluding locations farther than 50 miles as outliers, the estimated average straight-line commuting distance is 12 miles. This report assumes an estimated real-world driving distance of 1.26 times the straight-line distance, ${ }^{4}$ or an average one-way commuting distance of 16 miles for BTMO-member employees. ${ }^{5}$

The total-trip (a trip is defined as a one-way, or one-half of a daily commute) employee travel distance is estimated to be 16 VMT. To determine the number of miles avoided, the total trips were multiplied by this 16-mile average, with results shown in Figure 3. The total VMT avoided

\footnotetext{
${ }^{4}$ To convert from straight-line distance to "real-world" driving distances, a random sample of ZIP codes was selected and run through a driving-directions program.

${ }^{5}$ This is comparable to other methodologies, including the 1999 State of the Commute (SCAG 2000), which reported a mean driving distance for employees of 16.2 miles.
} 
is more than 1 billion miles for 1992 through 2005. This is an average of 78 million miles avoided annually.

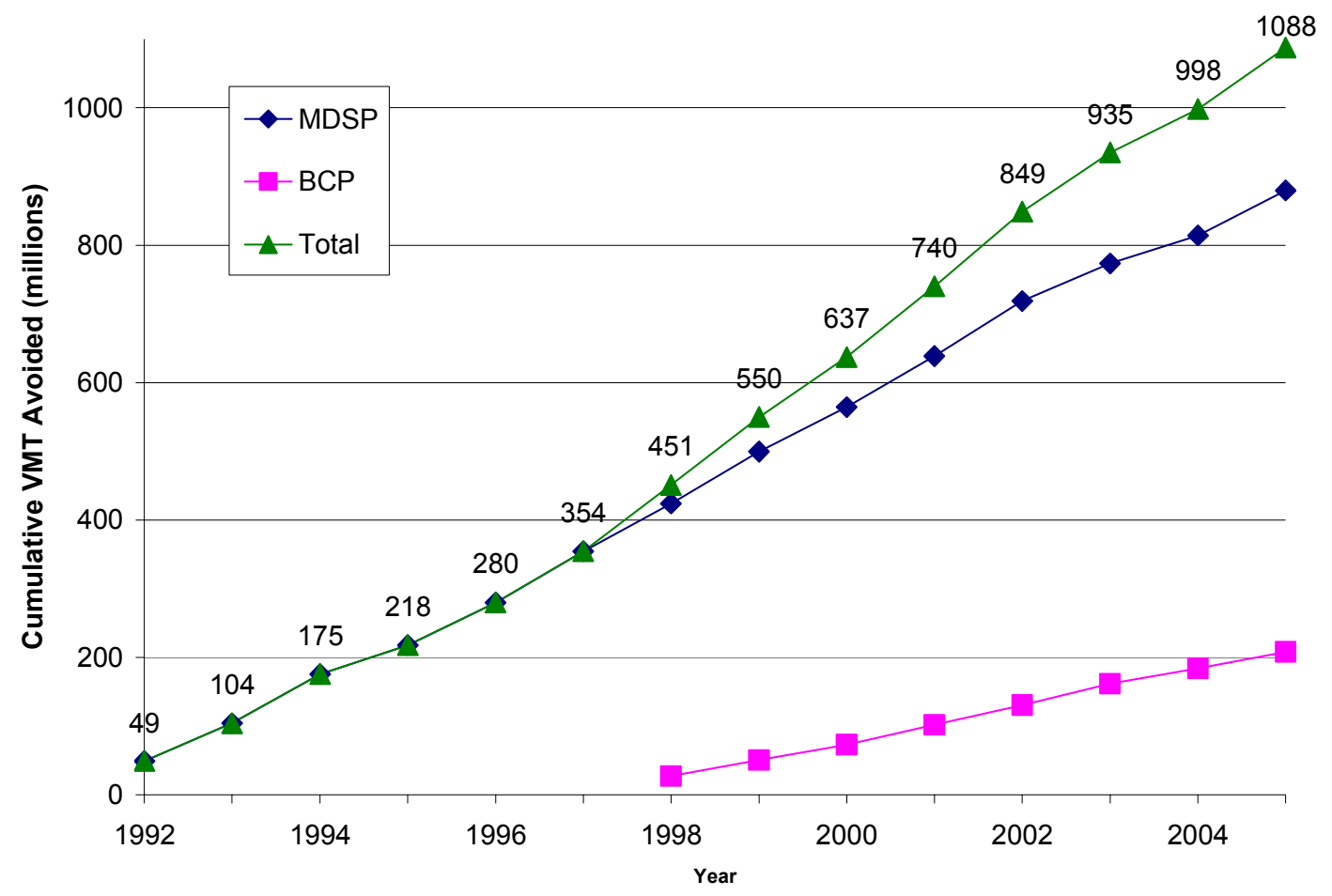

Figure 3. Cumulative VMT Reductions Attributed to BTMO-Member Companies

This understanding of trips and VMT avoided allows for a more direct connection to non-traffic impacts of the BTMO programs. The following sections address the methodology for determining the following benefits:

- Gasoline-consumption savings: gallons and cost avoided

- Pollution-reduction impacts: equivalent $\mathrm{CO}_{2}$ emissions reductions

- Productivity benefits: commuting time avoided

- Limited economic benefits: costs avoided

\section{Gasoline Consumption Avoided}

Due to increasing concerns regarding the U.S. dependence on foreign oil and increasing gasoline prices, effective traffic-reduction programs are important to document. To measure the impact of BTMO programs on gasoline consumption, annual gasoline savings were estimated based on BTMO member-company annual traffic-reduction reports, along with an assumed average oneway trip commute of 16 miles. Using average fuel-economy estimates for cars and trucks (DOE 2004 ) it is estimated that the average annual avoided gasoline consumption due to the BTMO activities is about 1 million barrels (44 million gallons). Table 2 shows the annual gasoline gallons avoided. 


\begin{tabular}{|l|l|}
\hline \multicolumn{2}{|l|}{ Table 2. Annual Gallons Gasoline Avoided } \\
\hline Year & Gallons Avoided \\
\hline 1992 & $1,941,724$ \\
\hline 1993 & $2,188,190$ \\
\hline 1994 & $2,891,038$ \\
\hline 1995 & $1,701,937$ \\
\hline 1996 & $2,490,602$ \\
\hline 1997 & $3,033,912$ \\
\hline 1998 & $3,905,917$ \\
\hline 1999 & $4,032,157$ \\
\hline 2000 & $3,523,510$ \\
\hline 2001 & $4,197,669$ \\
\hline 2002 & $4,413,979$ \\
\hline 2003 & $3,432,038$ \\
\hline 2004 & $2,566,426$ \\
\hline 2005 & $3,557,181$ \\
\hline Cumulative Total & $\mathbf{4 3 , 8 7 6 , 2 8 1}$ \\
\hline
\end{tabular}

\section{Pollution Reduction Impacts: VOC, CO, NOx, and CO2eq avoided}

The combustion of fossil fuel in vehicles results in the emission of multiple pollutants. The primary pollutant emissions are VOC, $\mathrm{CO}$, and $\mathrm{NOx}$. Another useful metric, $\mathrm{CO}_{2} \mathrm{eq}$, measures the combined pollutant emissions produced by the carbon content in the fuel being burned (EPA 2005). $\mathrm{CO}_{2}$ eq is the conventional metric used by the Intergovernmental Panel on Climate Change (IPCC) - the body of the World Meteorological Organization and United Nations Environment Program that studies climate change - to measure the suite of pollutants responsible for climate change. In this report, the emissions-avoidance benefits of the BTMO programs are measured two ways: through the primary individual pollutants and collectively through $\mathrm{CO}_{2} \mathrm{eq}$. Because of the comprehensive nature of the $\mathrm{CO}_{2}$ eq metric in terms of combustion of fossil fuels, the numbers are not additive.

Avoided CO, VOC, and NOx emissions resulting from BTMO programs are calculated in a twostep process. First, annual emission factors from the South Coast Air Quality Management District (SCAQMD) ${ }^{6}$ in pounds per mile are used to determine the total amount of pollution reduced, due to avoided vehicle miles traveled. Second, estimated pollution reductions are adjusted to reflect the increasing cleanliness of all California vehicles from 1992 through 2005, due to technology improvements. ${ }^{7}$ Average annual and cumulative BTMO-member company specific results are illustrated by pollutant type in Table 3. The annual CO, VOC, and NOx emissions reductions achieved by BTMO member-company employees and technology changes can be seen in the figures included with Table 3.

\footnotetext{
${ }^{6}$ Burbank is located within SCAQMD.

${ }^{7}$ Using 1992 as the base year, the difference between emission rates in vehicles increases over time as a result of improved vehicle technology (SCAQMD). The emission reductions resulting from technology improvements are calculated as the change in emissions between how much each vehicle would have emitted, if there were no technological improvement from 1992 forward.
} 


\begin{tabular}{|l|l|l|}
\hline \multicolumn{3}{|l|}{$\begin{array}{l}\text { Table 3. Annual average and cumulative } \\
\text { pollutant reductions attributed to BTMO- } \\
\text { member company efforts (1992-2005) }\end{array}$} \\
\hline Pollutant & $\begin{array}{l}\text { Annual Average } \\
\text { Reduction (tons) }\end{array}$ & $\begin{array}{l}\text { Cumulative } \\
\text { reduction } \\
\text { (tons) }\end{array}$ \\
\hline VOC & 79 & 1,100 \\
\hline CO & 664 & 9,300 \\
\hline NOx & 60 & 843 \\
\hline
\end{tabular}

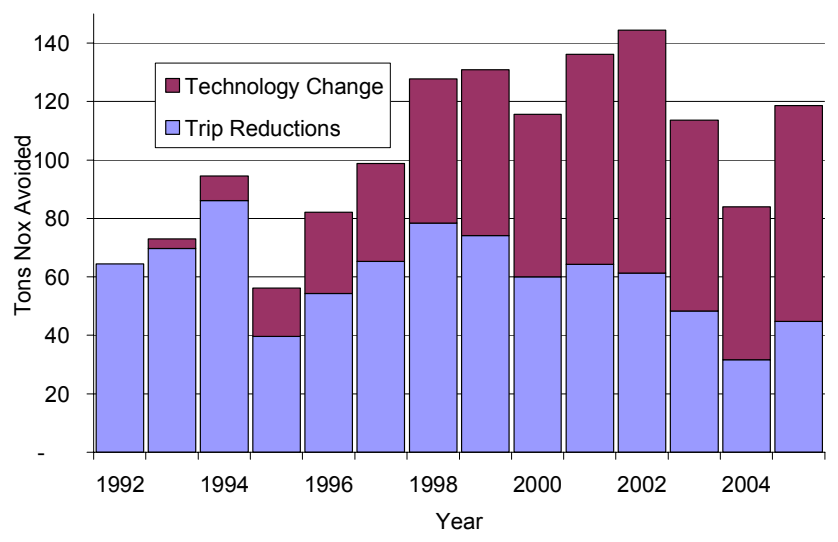

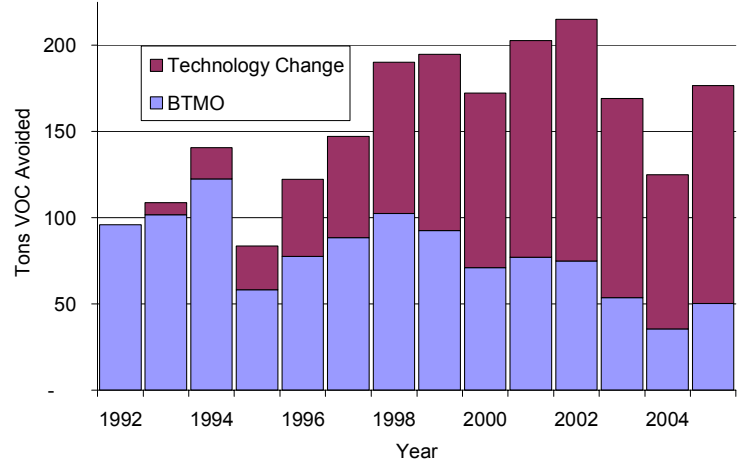

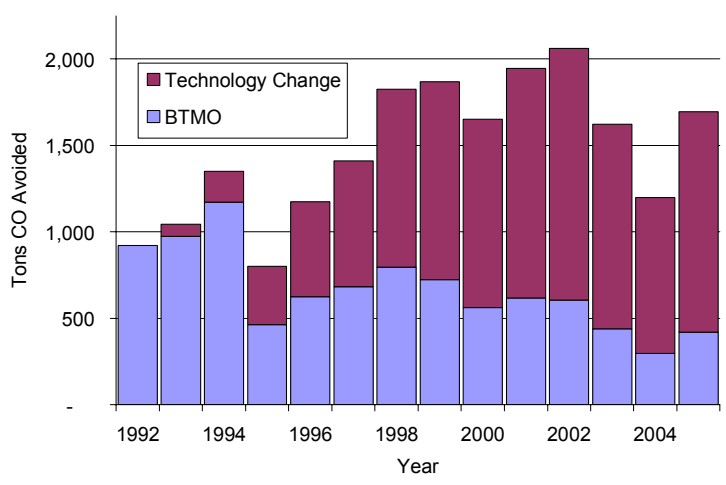

Pollution-Reduction Impacts: Equivalent $\mathrm{CO}_{2}$ Emissions Avoided

Gasoline combustion results in the production of multiple pollutants. Previously developed methodologies (see EPA 2005) allow for the expression of these pollutant impacts through a single metric - carbon dioxide equivalents $\left(\mathrm{CO}_{2} \mathrm{eq}\right)$ - allowing for comparison between fuels, technologies, and outputs in terms of climate change impacts. There are an estimated 19.4 pounds of $\mathrm{CO}_{2}$ eq in every gallon of gasoline combusted in mobile sources (EPA 2005). Based on the volume of gasoline avoided as a result of the trip-reduction programs, the emissions avoided represent approximately 425,000 tons of $\mathrm{CO}_{2}$ eq (Table 4 includes annual tonnage offset) or an average of more than 30,000 tons per year. Contextually, this cumulative amount of $\mathrm{CO}_{2} \mathrm{eq}$ is comparable to planting 119,000 acres of trees over the life of the BTMO program.

\section{Productivity Benefits}

Direct productivity time impacts are expressed in commuting hours avoided. Based on an average one-way commute time of 32.5 minutes, ${ }^{8}$ the total direct productivity time as a result of the BTMO traffic-reduction programs from 1992 through 2005 is 32 million hours with an annual average savings of more than 3 million hours.

\footnotetext{
${ }^{8}$ SCAG 2000 reports a round-trip travel time of 75 minutes, based on a 32-mile, round-trip commute. This translates to a 32.5 minute, 16-mile, one-way commute.
} 


\begin{tabular}{|l|l|}
\hline \multicolumn{2}{|l|}{ Table 4. Annual $\mathbf{C O}_{2}$ equivalents avoided } \\
\hline Year & $\mathbf{C O}_{\mathbf{2}}$ eq reduced (tons) \\
\hline 1992 & 18,800 \\
\hline 1993 & 21,200 \\
\hline 1994 & 28,000 \\
\hline 1995 & 16,500 \\
\hline 1996 & 24,200 \\
\hline 1997 & 29,400 \\
\hline 1998 & 37,900 \\
\hline 1999 & 39,100 \\
\hline 2000 & 34,200 \\
\hline 2001 & 40,700 \\
\hline 2002 & 42,800 \\
\hline 2003 & 33,300 \\
\hline 2004 & 24,900 \\
\hline 2005 & 34,500 \\
\hline Cumulative Total & 425,600 \\
\hline $\begin{array}{l}\text { Note: Total may differ from sum of annual numbers, } \\
\text { as a result of rounding. }\end{array}$ \\
\hline
\end{tabular}

\section{Economic Benefits: Gasoline and Productivity Benefits}

Because each hour of an individual's time has a market value, each hour spent in traffic congestion represents a cost. Average traveler's time is estimated to be worth $\$ 13.75$ per hour (Schrank and Lomax 2005). ${ }^{9}$ The average one-way commute time is assumed to be 32.5 minutes, based on estimates for southern California (SCAG 2000). Based on a total of 32 million hours avoided for member-company employees over the life of the programs, the program nets $\$ 584$ million in economic productivity benefits.

Avoided gasoline consumption also results in cost savings for BTMO member-company employees. To quantify the benefit, the number of gallons not consumed annually is multiplied by southern California average annual gas prices from 1992 through 2005 (CEC 2005). This results in a cumulative savings of more than $\$ 74$ million and an average annual savings of $\$ 5.3$ million. ${ }^{10}$

\section{Other Potential Benefits}

There are other potential benefits that can be defined and quantified for BTMO members and stakeholders, including the economic benefits of infrastructure improvement and the impact of reduced congestion on nonmember companies. These further benefits, as well as the ones quantified in this report, could be greatly improved if data collection was geared more toward quantifying them as well as straight traffic reductions. Further, calculating actual reductions in trips from one year to the next, instead of resetting the baseline each year, would allow for a more rigorous assessment of pollution reduction - especially important in a market where carbon reductions have an economic value.

\footnotetext{
${ }^{9} 2003$ estimate, the most recent year for data availability

${ }^{10}$ For consistency, annual savings is converted to 2005 equivalent dollars.
} 


\section{Recommendations}

The results of this evaluation show costs avoided, pollutant reduction, and congestion-reduction benefits resulting from the Burbank Transportation Management Organization's programs, specifically its demand-management and congestion-reduction programs in Burbank, California, for which it provided annual member data. This report focuses on the outcomes of the programs. It is important to emphasize that the benefits reported here are a result of the current program structure and the data available for analysis.

The following recommendations fall into two categories: program recommendations, and measurement and verification recommendations. Program recommendations target the continuation of the current cooperation between the parties involved to maintain current trafficreduction and cost-savings accomplishments and expand these into the future. The measurement and verification recommendations target the specifics of expanding and improving data identification and collection to more effectively measure program activity and benefits. By expanding the current data collection, it will be easier to collect and analyze information concerning emissions reductions, gas savings, and employee productivity improvements. If implemented, these recommendations could achieve continued savings as well as easier quantification and reporting of program benefits, increased credibility, and verification of savings.

\section{Programmatic Recommendations}

- The Importance of Continued Efforts. The analysis here indicates measurable benefits; and given the magnitude of those, the BTMO should consider continuation of its efforts. It is clear from this report that the current BTMO traffic-reduction programs are successful in reducing traffic congestion, vehicle miles traveled, and emissions from mobile sources. Some BTMO-member companies have reported relatively high rates of employee turnover (especially in restaurant and retail environments), creating a need for continued education of new employees just to maintain the current employee traffic reductions and cost savings. Continued efforts by the BTMO will provide for maintenance of current reductions achieved and the opportunity for greater long-term savings.

- Program Expansion. In addition to continuing the BTMO trip-reduction member programs, expanding the BTMO suite of programs provides an opportunity for greater and more targeted cost and fuel savings, based on the information to which the BTMO already has access. For example, a Geographic Information Systems (GIS) study of employee travel patterns may reveal local opportunities to reduce trips, such as areas of high employee density that would be more conducive to vanpools or increased busing services. We recommend that BTMO explore and expand options to meet traffic/congestion reduction, continue to include air quality improvements (SCAQMD Rule 2202 ${ }^{11}$ ) data in its employer/employee surveys, and target members whose employee work schedules are conducive to implementing specific transportation demand-management and air quality programs such as telecommuting and compressed workweeks.

\footnotetext{
${ }^{11}$ For more information: http://ozone.aqmd.gov/trans/aqip.html
} 


\section{Evaluation Improvements}

- Increased Programmatic Feedback. We recommend the BTMO continue to keep open communication with its members to obtain information (which can be shared among its members only and, where appropriate, publicly) regarding the successes and failures of member-specific programs. Periodic surveys could be used to obtain this information. The information collected could be compiled into a "Best Practices" guide for employers and serve multiple purposes, to:

- increase programmatic feedback to member companies,

- measure program success,

- identify areas where additional activities would be most beneficial (e.g., increased top management involvement in traffic-reduction activities.), and

- promote the success of companies having a positive impact on the environment

- Data Collection. One of the challenges in this analysis was extrapolating from a very small-scope survey over a long-term program. The current data collection formula uses a one-week, 4 to 6 p.m. survey. This method of data collection minimizes the burden on the BTMO member, but it is important to the continued success of the BTMO programs to understand the larger traffic patterns in the area, especially for credible measurement and verification of benefits, especially emissions reductions.

To maintain a minimal burden on the BTMO member, however, we recommend that the weeklong survey be maintained, but that the BTMO asks its members to report all data collected for employees rather than just the 4 to 6 p.m. commute information. As it is currently understood by NREL, BTMO-member companies already request employees to report their arrival and departure times by mode of travel for the week, but that only the 4 to 6 p.m. activity is reported to the BTMO. If all commutes are collected by many member companies, and reported to the BTMO, there will be a better and clearer understanding of the total commute activity occurring. While the BTMO may not need to publicly report this information, the new data will enable the BTMO and its members to know the actual traffic reduction, air quality, and other benefits occurring as a result of the BTMO programs. Thus, this recommendation specifically addresses the reporting mechanism to the BTMO. The benefit of this formula is the larger coverage of commuters and the clearer picture of travel patterns in Burbank.

Ideally, BTMO-member companies will submit employee commute information through a Web-based system that could collect and compile daily data. This type of data collection would allow BTMO members to identify changes in employee commute behavior based on seasonal and economic factors as well as document, in real time, the specific impacts of BTMO programs. 


\section{References}

[BTMO] Burbank Transportation Management Organization, trip-reduction program results data.

[Burbank] City of Burbank, California. Department of Planning. Local Area Specific Plan Descriptions. http://www.burbankca.org/planning/specificplans.htm

[CEC] California Energy Commission. 2005. Gasoline Prices per Gallon 1970 to 2005. URL: http://www.energy.ca.gov/gasoline/statistics/gasoline_cpi_adjusted.html, accessed 6/23/2006.

[DOE] U.S. Department of Energy, Oak Ridge National Laboratory, "Transportation Energy Data Book" (ORNL-6973), Edition 24, December 2004.

[EPA] Environmental Protection Agency. 2005. Metrics for Expressing Greenhouse Gas Emissions: Carbon Equivalents and Carbon Dioxide Equivalents. EPA420-F-05-002. Washington, D.C.: EPA

Schrank, D. and Tim Lomax. 2005. The 2005 Urban Mobility Report. Texas Transportation Institute, The Texas A\&M University System: Texas.

[SCAG] Southern California Association of Governments, Southern California Rideshare. 2000. 1999 State of the Commute Report. SCAG: Los Angeles, Ca. 


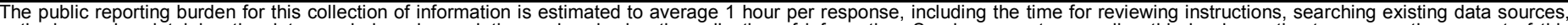

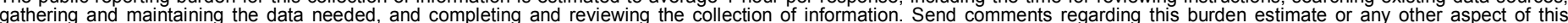

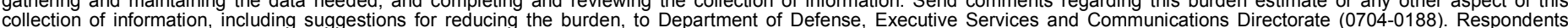

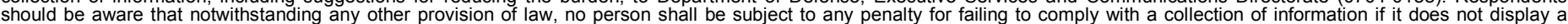

should be aware that notwithstanding

PLEASE DO NOT RETURN YOUR FORM TO THE ABOVE ORGANIZATION.

\begin{tabular}{l|l|l|l} 
1. REPORT DATE $(D D-M M-Y Y Y Y)$ & 2. REPORT TYPE & 3. DATES COVERED (FrOm - TO)
\end{tabular}

November 2006

Technical Report

4. TITLE AND SUBTITLE
Burbank Transportation Management Organization:

Impact Analysis

5a. CONTRACT NUMBER

DE-AC36-99-G010337

5b. GRANT NUMBER

5c. PROGRAM ELEMENT NUMBER

6. AUTHOR(S)

E. Brown and J. Aabakken 5d. PROJECT NUMBER

NREL/TP-640-40507

5e. TASK NUMBER

WW98.1000

5f. WORK UNIT NUMBER
7. PERFORMING ORGANIZATION NAME(S) AND ADDRESS(ES)

National Renewable Energy Laboratory

1617 Cole Blvd.

Golden, CO 80401-3393

9. SPONSORING/MONITORING AGENCY NAME(S) AND ADDRESS(ES)
8. PERFORMING ORGANIZATION REPORT NUMBER

NREL/TP-640-40507
10. SPONSOR/MONITOR'S ACRONYM(S) NREL

11. SPONSORING/MONITORING AGENCY REPORT NUMBER

12. DISTRIBUTION AVAILABILITY STATEMENT

National Technical Information Service

U.S. Department of Commerce

5285 Port Royal Road

Springfield, VA 22161

13. SUPPLEMENTARY NOTES

14. ABSTRACT (Maximum 200 Words)

The Burbank Transportation Management Organization (BTMO), a private, membership-based, nonprofit organization dedicated to traffic reduction and air quality improvement, contracted with the National Renewable Energy Laboratory (NREL), a U.S. Department of Energy-owned, contractor-operated national laboratory, to analyze its member programs and their benefits and effects. This report uses trip data collected by the BTMO, and defines and implements a methodology for quantifying non-traffic benefits such as gasoline savings, productivity, and pollution reduction.

15. SUBJECT TERMS

Burbank Transportation Management Organization; BTMO; analysis; transportation; consumers; energy; oil; gasoline; fuel; fuel-efficient vehicles; gas prices; trip reduction; vehicle miles traveled; carpool; parking; telecommuting; traffic reduction; Jørn Aabakken; Elizabeth Brown.

\begin{tabular}{|l|l|l|l|l|l}
\hline \multicolumn{3}{|l|}{ 16. SECURITY CLASSIFICATION OF: } & $\begin{array}{c}\text { 17. LIMITATION } \\
\text { OF ABSTRACT }\end{array}$ & $\begin{array}{c}\text { 18. NUMBER } \\
\text { OF PAGES }\end{array}$ \\
$\begin{array}{l}\text { a. REPORT } \\
\text { Unclassified }\end{array}$ & $\begin{array}{c}\text { b. ABSTRACT } \\
\text { Unclassified }\end{array}$ & $\begin{array}{l}\text { c. THIS PAGE } \\
\text { Unclassified }\end{array}$ & $\begin{array}{c}\text { UL } \\
\end{array}$ & &
\end{tabular}

19a. NAME OF RESPONSIBLE PERSON

19b. TELEPHONE NUMBER (Include area code) 